\title{
Noncoronary Collateral Myocardial Blood Flow: The Human Heart's Forgotten Blood Supply
}

\author{
Marco Picichè* \\ Cardiac Surgery Department, San Filippo Neri Hospital, Via Martinotti 20, 00135, Rome, Italy
}

\begin{abstract}
The "noncoronary collateral circulation" (NCCC) or "noncoronary collateral myocardial blood flow" (NCCMBF), reaches the heart through a micro-vascular network arising from the bronchial, esophageal, pericardial, diaphragmatic, and aortic arteries. The left and right internal thoracic arteries (ITAs) along with their collateral branches also serve as a source of NCCMBF-a feature seen in other mammals. Under certain circumstances the ITAs have a high potential for developing collateral branches. In the case of severe Leriche syndrome or with chronic obstruction of the abdominal aorta, the ITAs can serve as the main or even sole source of blood supply to the lower limbs. It is also possible for the ITAs to develop angiographically visible branches that directly connect with the coronary arteries. In ischemic conditions there is a functional, ischemia-reducing extracardiac coronary artery supply via natural ipsilateral ITA anastomosis. To date we know little about NCCMBF and its potential benefits in clinical applications, which makes this a challenging and intriguing field of research. This paper reviews all available data on noncoronary collateral blood supply to the human heart.
\end{abstract}

Key-words: Collateral circulation, Noncoronary collateral blood flow, Internal thoracic artery, Ischemic heart disease, Myocardial revascularization, No-options patients.

\section{INTRODUCTION}

Despite commonly held beliefs that the coronary arteries constitute the only source of myocardial perfusion, and that coronary collateral circulation (CCC) is the only blood supply that warrants ongoing attention [1, 2], there is adequate evidence to suggest that the human heart benefits from a small additional source of blood. Called "noncoronary collateral myocardial blood flow" (NCCMBF) or "noncoronary collateral circulation" (NCCC), it reaches the heart from the arteries of surrounding structures [3-9], and relative to $\mathrm{CCC}$ is seldom investigated. The left and right internal mammary arteries (ITAs), along with their collateral branches, are among these non-coronary sources [7-10]. This paper reviews the available data on noncoronary blood supply to the human heart.

\section{The Nature of NCCMBF}

Phylogenesis and comparative anatomy - Extra-coronary sources of blood supply exist in mammals other than man. This can be understood from a phylogenetic perspective. Gill-breathing vertebrates possess both coronary and extracardiac arteries that arise from a position homologous to the upper dorsal aorta. As the lungs replaced the gills, the heart migrated caudally from the cervical to the thoracic region. The site of origin of the coronary arteries also migrated caudally to draw closer to the source of oxygenated blood

*Address correspondence to this author at the Cardiac Surgery Department, San Filippo Neri Hospital, Via Martinotti 20, 00135, Rome, Italy; Tel: 0039-389-157.02.08; E-mail: marco.piciche@libero.it
[11]. Along with the migrations of the heart and coronary arteries, extra-cardiac vessels shifted from the upper to lower part of the dorsal aorta. Hence, extra-cardiac sources of blood supply in mammals are reminiscent of the extracardiac system found in gill-breathing vertebrates [12]. A dual blood supply may be observed in dogs, where there is an anastomotic network between the right internal thoracic artery (RITA) and the right coronary artery (RCA) [13, 14]. This network reaches the heart by crossing the surface of the superior vena cava. Dual circulation is well developed in the rat heart; indeed, both right and left cardio-mediastinal arteries (CMAs) exist [14]. In most cases the right CMA arises from the RITA and less frequently from the carotid system, while the left CMA generally arises from the left internal thoracic artery (LITA) and in about $10 \%$ of the cases from the left subclavian artery and much less frequently from the first intercostal artery. The CMAs cross the chest from a lateral to medial position, traversing the anterior surfaces, respectively, of the right and left superior venae cavae - the latter usually present in the rat. Once they reach the heart, they divide into deep and superficial branches. The deep branches turn towards thoracic structures, establishing anastomoses with tracheobronchial and esophageal arteries, while the superficial branches divide into lateral, medial, and central sub-branches that perfuse the left and right atria, the conduction system, and the pulmonary veins. The nodal artery that perfuses the sino-atrial node usually arises directly from the RITA; thus, the conduction system of the rat is especially protected by both extra-coronary and coronary sources [14].

Human anatomy - In man, the vascular network of extracardiac arteries was first studied by Albrecht von Aller, 


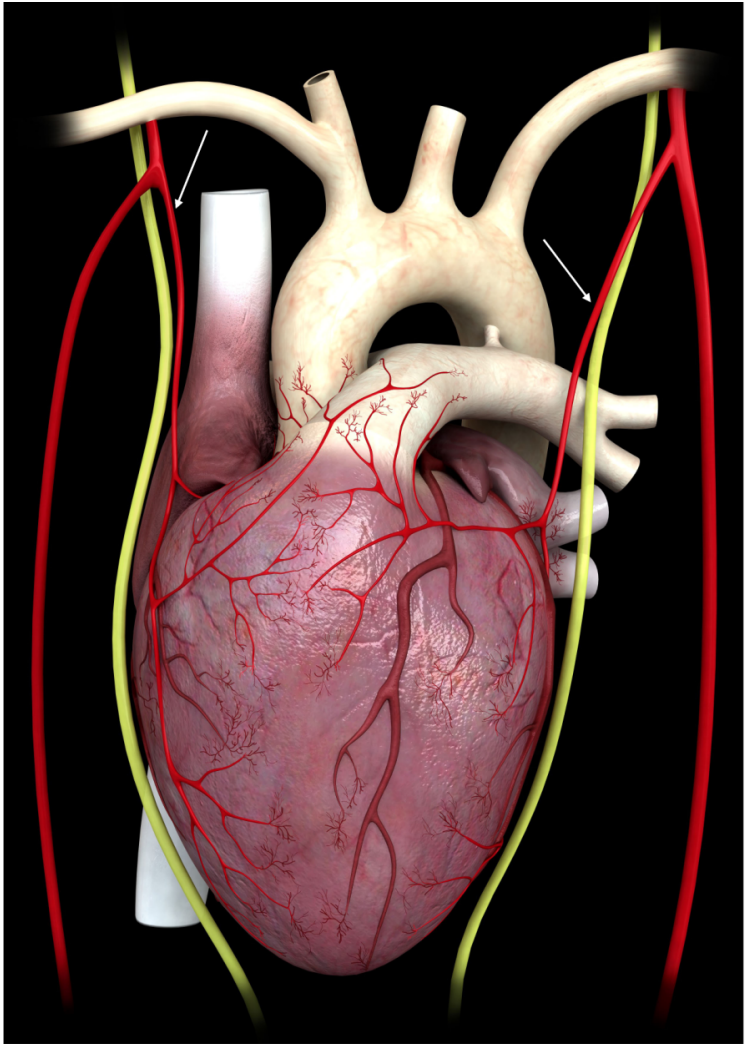

Fig. (1). The internal mammary arteries give origin to the pericardiophrenic artery (arrows), which runs parallel to the phrenic nerve, through which it establishes connections with the heart.

who, in 1803 , identified communications with the coronary arteries [15]. Some decades later, Langer, by injecting the coronary ostia, established that connections exist between the coronary arteries and the mediastinal, parietal pericardial, diaphragmatic, and hilar pulmonary arteries-he published his observations in 1880 [16]. In 1926, Woodfrood demonstrated connections between the aortic vasa vasorum and the coronary arteries [17]. Two years later Wearn confirmed that after injecting a colorant in the coronary ostia, the aortic vasa vasorum colored in the same way [18]. Robertson emphasized the importance of pericardial fat arteries in cases where there is obstruction of the coronary arteries. He described, as did the above-mentioned authors, the anastomosis between the coronary arteries, the small vessels of the aortic adventitia, and other vessels of the chest [19]. Further research on this was carried out by Gross [20], Monckberg [21], Spalteholz [22], Warburg [23] and Krasner [24]. In more recent years, studies performed by Brazier and Buckberg pursued the best method to achieve myocardial protection during open heart surgery and described the risk of cardioplegic solution wash-out due to noncoronary blood supply [4]. They determined that this blood supply could be attributed to "noncoronary collateral myocardial blood flow." The anatomy was detailed by Hudson, Moritz and Wearn [6] as follows: (1) around the origin of the coronary arteries are micro-vascular arteries connecting to the aortic vasa vasorum and the small arteries of the aortic adventitia, mediastinum, diaphragm, pericardium, and pericardial fat; (2) there are some coronary branches in the pulmonary infundibulum that connect with the small arteries of the pericardial reflections situated around the main pulmonary artery, and with the small vessels of the pulmonary arteries and their peripheral branches, i.e., the mediastinal, bronchial, and fatty tissue arteries; (3) around the pulmonary veins is a network connecting with the bronchial, mediastinal, and pericardial arteries; (4) around the ostia of the superior and inferior vena cava is a network communicating with atrial branches of the right coronary artery, aortic, and pulmonary vasa vasorum; and (5) around the great vessels are small arterioles in the pericardial reflections [4]. In autopsy studies it was demonstrated that the surrounding organs contributed branches to the heart. It was possible to demonstrate the passage of injection mass from the coronary arteries into the vessels of surrounding structures, as well as the passage of injection mass from the thoracic branches of the aorta into the heart [25]. The most important thoracic branch establishing connections with the heart is the pericardiophrenic branch of the ITA (Fig. 1). Other branches, in order of prominence, are the anterior mediastinal, pericardial, and bronchial arteries, the superior and inferior phrenic arteries, and the intercostal and esophageal branches of the aorta [6]. The thoracic branch sources of noncoronary blood supply have also been mapped by Bloor and Liebow [3] (Fig. 2). Connections are more developed in older patients in accordance with the observation by Robertson [19] and Gross [20] that arterial branches to the pericardial fat increase with age. This may be explained by the increased probability of ischemic heart disease in older people and their requirement for compensatory blood supply mechanisms.

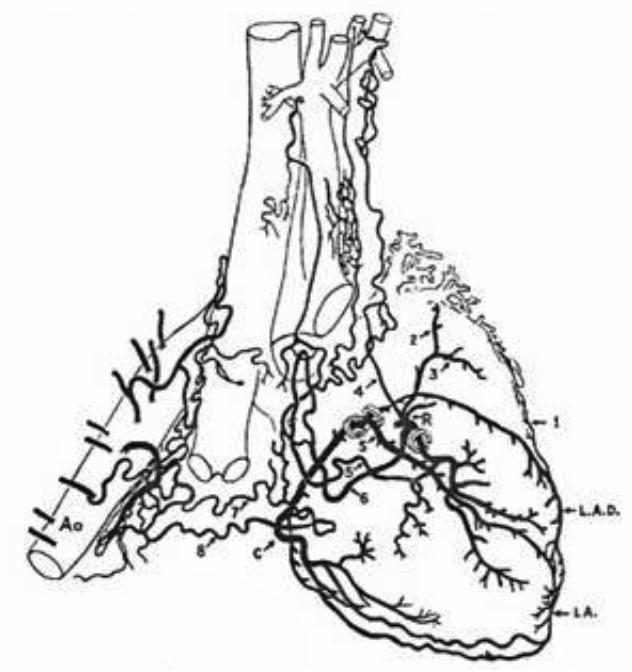

Fig. (2). The non-coronary sources of blood supply to the heart come from heterogeneous thoracic arteries (reprinted with permission from Bloor CM, Liebow AA. Coronary collateral circulation. Am J Cardiol 1956; 238-52).

Diameters, flow and physiology - The morphology of anastomosis may undergo change when pathologic conditions are present. Vessels can increase in caliber and become tortuous [10]. The diameters range from less than 1 $\mathrm{mm}$ up to $3 \mathrm{~mm}$ [25-30]. Vessels may reach a diameter of 2 $\mathrm{mm}$ in one out of eight patients $[28,29]$-Kawasuji reported a vessel that reached $3 \mathrm{~mm}$ in diameter [30]. Nevertheless, 
even in patients with normal coronary arteries, anastomoses between the bronchial and atrial vessels of the coronary arteries are large enough to be seen by angiography. This important feature is said to exist in $20 \%$ of all humans [28].

Several investigators have attempted to estimate NCCMBF in dogs in the course of cardiopulmonary bypass using radioactive microspheres. Brazier and coworkers reported a flow rate ranging from 12 to $16 \mathrm{ml} / 100 \mathrm{~g} / \mathrm{min}$ [4]. They found that flow was greatest when the heart is arrested by aortic cross-clamping and in cases of ventricular hypertrophy. The authors suggested that NCCMBF might provide sufficient oxygen to the arrested left ventricle when metabolic needs are diminished due to hypothermic cardioplegia. Goldstein and associates found a mean NCCMBF rate of $3.4+/-0.16 \mathrm{ml} / 100 \mathrm{~g} / \mathrm{min}$ following pharmacologic arrest with a range of from 8 to $261 \mathrm{ml} / \mathrm{min}$ [31]. In some patients the authors found no flow and attributed this to inaccuracies in the way the measurement was conducted. In a study by Baile et al., the NCCMBF ranged from 2.28 to $75 \mathrm{ml} / \mathrm{min} / 100 \mathrm{~g}$, with a mean value of $14 \mathrm{ml} / \mathrm{min} / 100 \mathrm{~g}$ [32]. Coronary artery blood flow in normal resting patients has been reported to be $80+/-11 \mathrm{ml} / \mathrm{min} / 100$ $\mathrm{g}$ in one study [31] and $66+/ 25 \mathrm{ml} / \mathrm{min} / 100 \mathrm{~g}$ in another [33]. So according to these measurements, NCCMBF is about one fifth that of coronary flow [32].

Noncoronary collateral vessels have the capacity to enlarge in response to pathologic conditions. The direction of flow depends on the conditions. In the case of supravalvular aortic stenosis, coronary arterial pressure increases and flow moves from the coronary arteries to the bronchial arteries [34]. This also occurs when bronchial arterial pressure decreases, as in Fallot tetralogy presenting pulmonary atresia [35] or stenosis [36]; or in the event of a pulmonary artery obstructive lesion, as is the case in Takayasu's arteritis, in which flow runs to the pulmonary circulation through the bronchial arteries [30]. Conversely, blood flow is directed to the heart when the pressure regimen is reduced in coronary arteries due to stenosis or occlusion $[26,28]$. It has been reported that these anastomoses are more frequent in patients suffering from ischemic heart disease-being present in 50\% of patients-rather than in people who do not suffer from ischemic heart disease, where they are present in $20 \%$ of the cases [28]. It has also been reported that the greater the severity of coronary stenosis, the greater the size of the anastomotic vessels [28]. There is further evidence of flow directed to the heart in angiographically documented cases of direct anastomoses between the ITAs and coronary arteries [37-41].

\section{Observations from Clinical Practice}

In cardiac surgery it is sometimes possible to observe blood pouring out of the coronary ostia while the aorta is open during aortic valve or ascending aorta procedures $[4,7$, 8]. During CABG it is often possible to observe blood coming from the coronary arteriotomy. This can make the surgeon's work more arduous due to reduced visibility at the anastomosis site $[5,7,8]$. This phenomenon may be observed despite proper cross-clamping of the ascending aorta and the positioning of a decompression line (vent).
Also, at times the heart does not cease beating or continues to fibrillate despite administration of a full dose of cardioplegic solution and adequate clamping of the aorta. Some angiographic scenarios point to additional conditions that imply the existence of a dual blood supply for the heart. The heart may continue to preserve good ventricular function despite the coexistence of a severely stenotic/occluded/ hypoplastic right coronary artery with a critical left main stem, or with total occlusion of two coronary arteries and sub-occlusion of a third [4, 42, 43]. If we acknowledge that under these circumstances blood supply from the coronary arteries is not sufficient to assure normal oxygenation and contractility, then preservation of an ejection fraction exceeding $55 \%$ can only be achieved through the existence of a secondary source of nourishment. Some rare autopsy studies on patients with chronic occlusion of three coronary arteries who died from non-cardiac causes indirectly support this assertion. Leary and Wearn reported on two autopsy cases having an intact endothelium and no thrombi in the coronary lumen, in spite of the apparent occlusion and hyalinization of the arteries due to a progressive chronic process [44]. Thorel reported the case of a man who died from carcinoma and whose coronary arteries at autopsy appeared to be obliterated proximally and over a long period of time. That patient presented extensive pericardial adhesions, and the heart had been nourished by neo-vessels existing in adherent scars [45]. These reports date from years ago, and prudent interpretation is advisable. However, it is a fact that the theory of neo-channel development within intrapericardial adhesions was adopted by many research surgeons of the pre-cardiopulmonary bypass era who were seeking a myocardial revascularization method. They created intra-pericardial adhesions in a number of ways; including injecting irritant agents in the pericardial cavity [46]; using skeletal muscle flap techniques [46-49]; and with cardioomentopexy $[46,50]$, cardiopneumonopexy [46, 51, 52] cardiojejunopexy $[46,53]$, and gastrocardiopexy procedures $[46,54]$. The results were variable, depending on the technique, but some of these procedures succeeded in supplying the heart through artificially created extracoronary circulation channels. They did not limit themselves to animal experimentation models but also developed myocardial revascularization procedures for humans [46-49]. They had some success relieving patients' angina or even returning them to work activities [47]. These outcomes demonstrated that, in cases of coronary insufficiency, the heart could be nourished through clinical improvements brought about by the development of artificially created noncoronary sources. Similarly, under ischemic conditions the heart may be nourished by naturally occurring extracoronary blood supply sources. The latter would explain the good ventricular function seen in patients with almost total occlusion of all three coronary arteries, as well as the aforementioned phenomena observed during cardiac surgery. In this view, NCCMBF may serve as a compensatory mechanism in the presence of pathologic conditions. NCCMBF has been visually observed, presenting as an outpouring of blood from the coronary arteriotomy site in 16 of 58 patients - a total of 22 out of 168 coronary arteries were evaluated - affected by ischemic heart disease who had undergone $\mathrm{CABG}$ [5]. It was not merely a coincidence that 

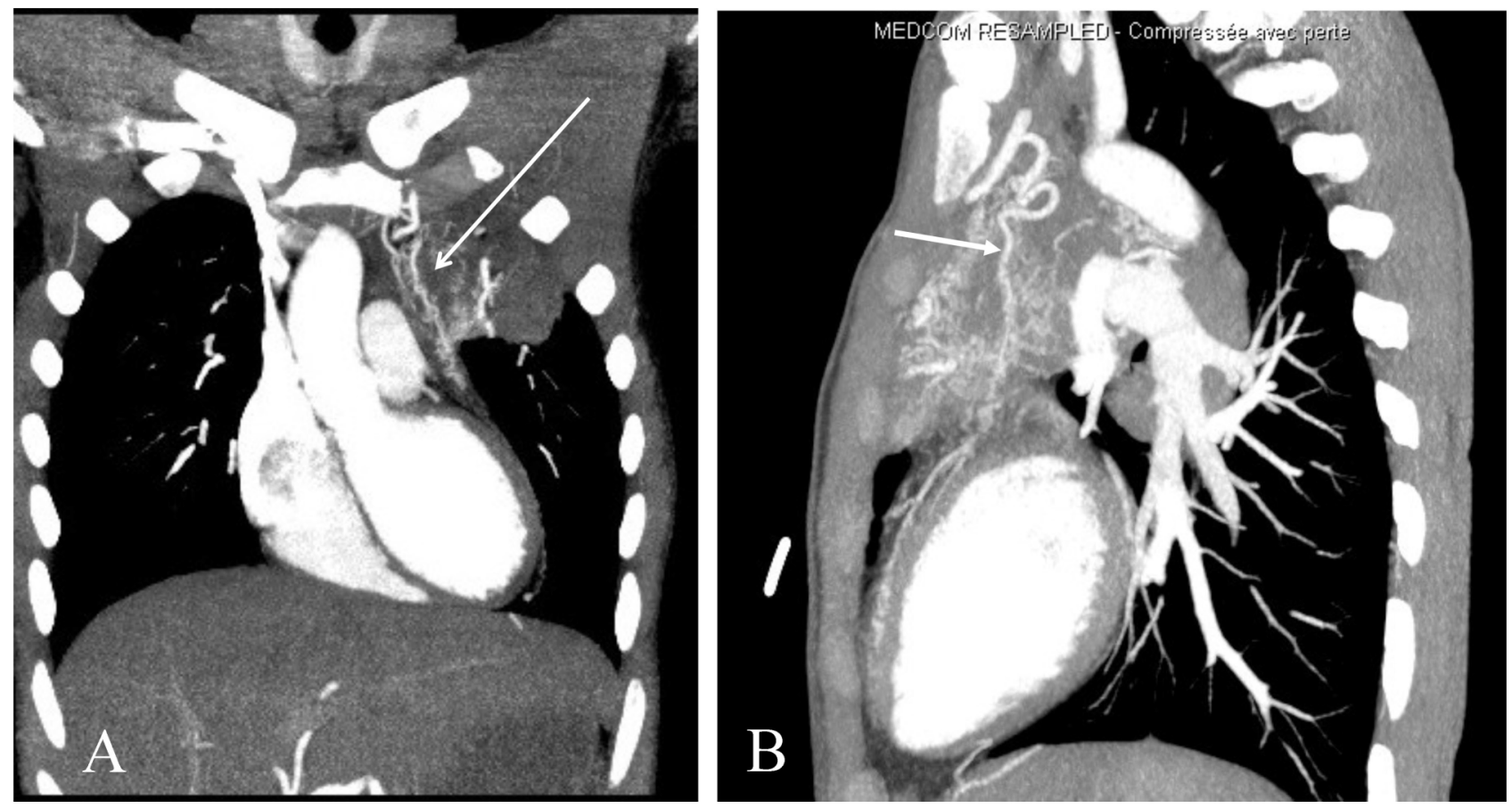

Fig. (3). An angio CT scan showing a branch arising from the internal mammary artery directed to the heart in a patient affected by a pulmonary infection and ischemic heart disease. The artery is visible both in the frontal (A) and sagittal (B) planes (arrows).

this was observed more frequently in patients with triplevessel disease $(34 \%)$ and in patients presenting with, rather than without, $(\mathrm{p}<0.005)$ intercoronary collateral flow at angiography [5]. This suggests that the increase in NCCMBF provided an alternative blood supply during myocardial ischemia. In myocardial biopsies from dogs subjected to cardiopulmonary bypass and cardioplegic arrest, the presence of erythrocyte-filled blood vessels pointed to the possibility of direct access of NCCMBF to the heart, despite correct aortic cross-clamping [55]. Notwithstanding the compensatory effect of NCCMBF in ischemic heart disease, its role in cardiac surgery may be detrimental. Very few authors suggested that NCCMBF could reduce ischemic injury [55]. The majority believed NCCMBF could be detrimental because it can cause cardioplegic solution wash out, which in turn precipitates renewed electromechanical activity and the failure of perioperative heart protection $[4,5$, $33,34]$.

\section{The ITAs' Potential for Developing Collateral Branches}

The ITAs each arise from the left and right subclavian arteries. They run in a cranio-caudal direction beneath the parietal pleura, 3 to 4 centimeters away from and parallel to the sternal border. The branches of the ITAs consist of the anterior intercostal, pericardiophrenic, perforating, muscolophrenic, and superior epigastric arteries [56-59]. The ITAs have the potential for developing collateral branches under some circumstances. It has been widely demonstrated that in cases with severe Leriche syndrome or with chronic obstruction of the abdominal aorta, the ITAs can evolve into the main or even sole source of blood to the lower limbs [6068]. The latter occurs by virtue of the superior epigastric terminal branch, which shunts blood flow to the inferior epigastric arteries, which then anastomose with the external iliac arteries, eventually bypassing the aortic obstruction. It is also possible for the ITAs to develop angiographically visible branches that directly anastomose with the coronary arteries. This latter phenomenon has been demonstrated in several patients for both the right $[37,38]$ and left ITA [3941]. Recently the author of this manuscript reported on a collateral branch arising from the left ITA directed towards the left anterior descending artery in a patient affected by a pulmonary infection and ischemic heart disease (Fig. 3A, B) [69]. Autopsy results from patients who died from ischemic heart disease confirmed this potential for plasticity. Similar connections were found in $12 \%$ of the cadavers observed [10]. The potential of the ITA to form collateral branches was also the basis for the Vineberg operation performed in the 1940s. It involved implanting the left and/or right ITA into the left ventricle free wall, leading to the development of an extensive vascular network in the myocardium and relief from angina $[46,70,71]$. This network was evident angiographically even at long-term follow-up [72, 73]. More recently (1993), Unger et al. confirmed in canine models that implanting ITAs in intramyocardial tunnels improved ITA-derived collateral blood flow, provided nutritive supply, and improved left ventricular function. Also, continuous infusion of heparin, rather than acid fibroblast growth factor, promoted new ITA-related collateral anastomoses [74-76]. Another example of the ITAs' potential for collateralization was seen following imperfect coronary surgery, where blood flow was impeded by stenosis at the ITA-to-coronary artery anastomotic site, and eventually by graft occlusion in its middle-distal portion. In such a cases new branches arose from the ITAs and 


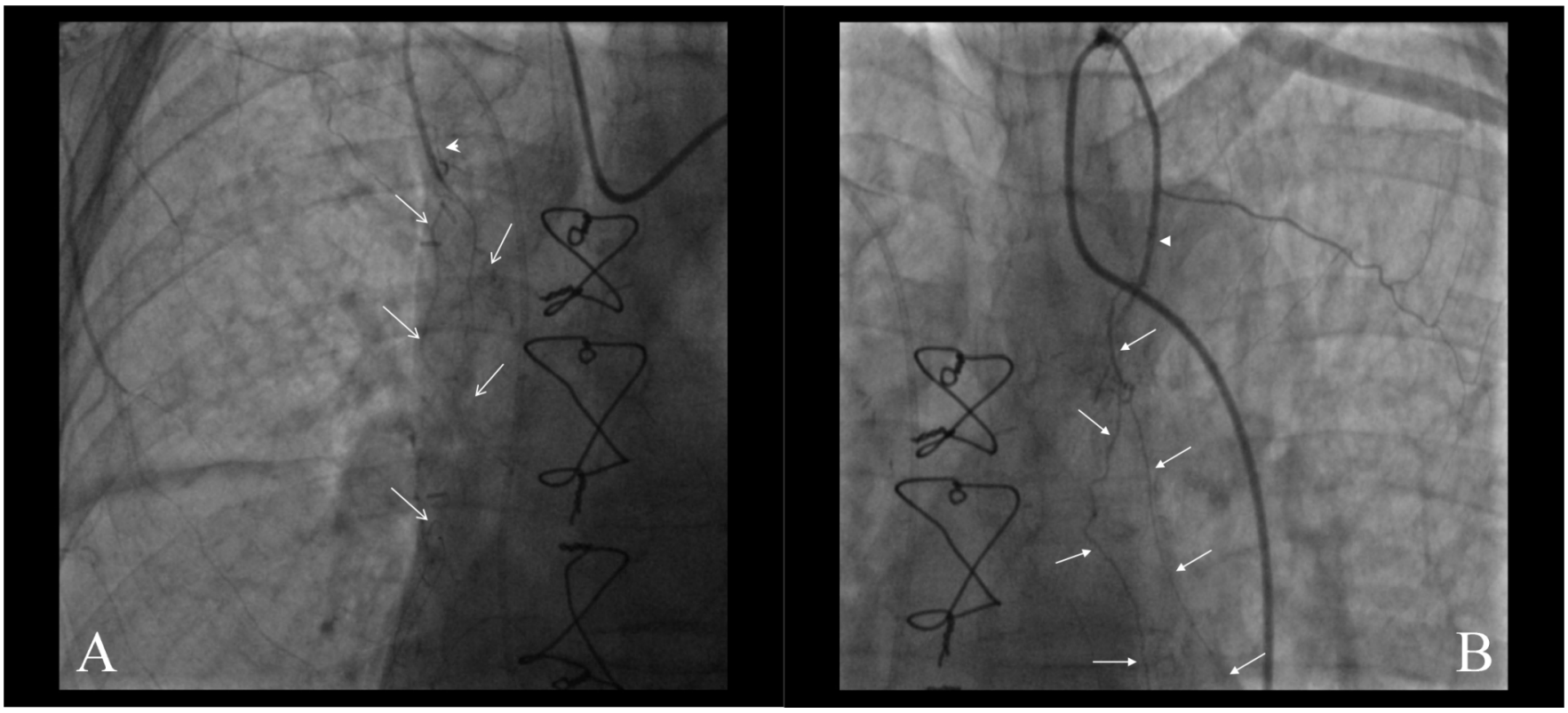

Fig. (4). Selective angiography of the right $(\mathbf{A})$ and left $(\mathbf{B})$ internal mammary arteries in a patient who had undergone a CABG procedure 20 days earlier. The IMAs appear occluded (arrowheads), but in both cases fine new branches had developed from the patent segments, directed towards the heart (arrows).

directed toward the heart within a few months of surgery [39]. However, this phenomena may be noticed even within a much shorter interval (Fig. 4A, B). These observations suggest that ITAs exhibit a significant potential for plasticity that may be induced under hypoxic conditions and/or in the presence of an obstruction to anterograde flow. Since ITA blood flow to the lower body increases with leg ischemia, one can speculate analogously that when blood flow is induced by a myocardial ischemic stimulus, it is preferentially diverted through branches directed to the heart rather than to the chest wall $[7,77,78]$.

Initial studies on ITA-related NCCMBF - Prior to the first successful on-pump open heart operation by Gibbon in 1953 [79-81], and the global spread of coronary surgery in the 1960s and 1970s [46, 82], myocardial revascularization was achieved through ingenious and heterogeneous techniques [46-54, 83-85]. Early research in the US by Claude S. Beck demonstrated that the heart could be revascularized by neovessels developed within artificially created pericardial adhesions [46-49, 86, 87]. In Italy in 1939, Davide Fieschi performed a surgical ligature of the internal mammary arteries in one patient [88]. The patient experienced no angina at two years follow up. World War II impeded research in this field but Battezzati et al. [89] adopted these methods again in the 1950s. The rationale was that ligature of the ITA caused a local hypertensive status that resulted in an increase in perfusion pressure within the channels leading to the heart, principally the pericardiphrenic artery. Surgical access consisted of bilateral incisions of a few centimeters under local anesthesia between the second and the third ribs [89-94]. In 1959 Battezzati reported very encouraging results in the Am J Cardiology on 304 patients [95]. He saw symptomatic improvement in $94.8 \%$ of the patients and electrocardiogram improvement in $64.1 \%$. The authors concluded that surgical ligation of the ITA produced "an increased blood supply to the myocardium through natural and pre-existing anastomotic channels" [95]. Follow-up ranged from 3 months to 4 years later. The clinical data confirmed what the same authors had proposed experimentally while working with canine models and human cadavers where they injected methylene blue into the mammary arteries and witnessed the onset of blue areas in the epicardium and in myocardial slices [89]. In Philadelphia, Glover demonstrated that ligation of the ITA prior to coronary artery occlusion prevented many dogs from dying, whereas all dogs died within 24 hours in the group in which coronary occlusion was not preceded by ITA ligation. Specifically, $58 \%$ of the dogs in the ligated group survived five days or more and $36 \%$ recovered completely. In humans, Glover' data confirmed Battezzati's encouraging results and the clinical value of the technique [96-98]. In 1958 Taber and Marchioro, working in canine models, observed a rise in subclavian artery pressure after ligation of the ITAs via an artificial-tubing system that replicated the ITA-pericardiophrenic artery system. They observed a rise of pressure in both arteries and concluded that blood flow through the pericardiophrenic artery may increase after ITA ligation [99]. Kitchell et al. reported that $68 \%$ of patients who had undergone ITA ligation found relief from angina [100]. Botham and associates, working with canine subjects, found that a consistent rise in pressure in the proximal segment of the ITA not only transmitted to its branches but also to the overall systemic and coronary arterial system. This suggested that such a generalized rise in pressure was due, in part, to neural and/or humoral factors [101]. This spurred a debate in the scientific community because other authors reported conflicting results. In 1959 and 1960, Cobb et al. [102] and Dimond et al. [103], respectively, also reported relief from angina in patients following a sham ITA 
ligation and so asserted that the placebo effect adequately explained the improvement in symptoms. However, just as the debate intensified the advent of cardiopulmonary bypass and on-pump coronary surgery relegated it to oblivion-that is until recently.

New studies on ITA-related NCCMBF - Since 2010, the author of this manuscript has sought to promote the principle of ITA occlusion through theoretical speculation based on a comprehensive reading of the historical record and more recent experimental work $[7,8,49,69,77,78,104]$. An experimental protocol was carried out in canine models. It involved LITA surgical occlusion, injection of vascular endothelial growth factor into the LITA, and the use of the neutron-activated microsphere technique. However, this first attempt in 50 years proved to be too onerous for the dogs, which were scheduled for three operations each [69]. In 2011, an anatomical report on this topic was published by Loukas et al. [9]. A very recent study by Stoller, De Marchi, and Seiler investigated the function of mammary-to-coronary artery anastomosis and its effects on myocardial ischemia in 120 patients [105]. This was done by calculating the collateral flow index (CFI) and intracoronary ECG ST segment elevation. The protocol involved induction of myocardial ischemia by coronary artery balloon occlusion with and without simultaneous distal ITA occlusion by angioplasty balloon. Complete occlusion of the ITA and the coronary artery was established by angiography. A total of 360 measurements were performed. The CFI was significantly higher in the presence versus the absence of IMA balloon occlusion $(p<0.0001)$. Also, intracoronary ECG ST elevation was significantly reduced in the presence versus the absence of simultaneous ITA occlusion, and angina tended to diminish. By adopting modern tools this study confirmed the old theory that there is a functional, ischemia-reducing extracardiac coronary artery supply via natural ipsilateral ITA anastomosis [105].

\section{NCCMBF and the Issue of 'No-option' Patients}

Despite the improvement in coronary artery bypass grafting and percutaneous coronary intervention techniques, there is still a considerable number of patients not amenable to conventional myocardial revascularization due to the presence of diffuse coronary artery disease or severe comorbidities, the so-called 'no-option' patients [106-109]. It is difficult to quantify the exact percentage of the population these patients represent but in daily practice this condition is encountered with increasing frequency due to the growth in the elderly population. It is estimated that in the United States alone, from 300,000 to 900,000 patients experience refractory angina pectoris, with some 25,000 to 75,000 new cases diagnosed each year [110]. Extrapolating, this means there are millions of patients worldwide suffering from angina pectoris whose only option is to receive medical therapy. Despite the advent of new drugs (e.g., Ranolazine [111], Ivabradine [112], and Nicorandil [113]) and the existence of non- pharmacologic treatments (e.g., transcutaneous electrical nerve stimulation [114], spinal cord stimulation [115], enhanced external counterpulsation [116], laser transmyocardial revascularization [117], extracorporeal shockwave myocardial revascularization [118]), the problems no-option patients face have not yet been resolved.
To date we know little about noncoronary blood supply to the heart and its potential benefits in clinical settings. That makes this both a challenging and intriguing topic for research. Aiming at enhancing the NCCMBF, there are many compelling arguments for pursuing research into the potential role of ITAs as an ipsilateral blood supply. Naturally this raises the question on how to achieve the therapeutic benefits.

Occlusion of ITAs has been successfully achieved in the past through surgical ligature, or more recently by experimental balloon inflation distal to the origin of the pericardiophrenic artery. Nowadays, occlusion of the middistal segments of the ITAs might be accomplished using an endovascular approach [77], i.e., embolization-a safe, low cost, and widely adopted endovascular procedure. It remains to be seen whether speculation along these lines can spur a new line of investigation that yields effective treatments for no-option patients.

\section{CONFLICT OF INTEREST}

The author confirms that this article content has no conflict of interest.

\section{ACKNOWLEDGEMENTS}

Declared none.

\section{REFERENCES}

[1] Zimarino M, D'Andreamatteo M, Waksman R, Epstein SE, De Caterina R. The dynamics of the coronary collateral circulation. Nat Rev Cardiol 2014; 11(4): 191-7.

[2] Seiler C, Stoller M, Pitt B, Meier P. The human coronary collateral circulation: development and clinical importance. Eur Heart J 2013; 34(34): 2674-82

[3] Bloor CM, Liebow AA. Coronary collateral circulation. Am J Cardiol 1965; 238-52.

[4] Brazier J, Hottenrott C, Buckberg G. Noncoronary collateral myocardial blood flow. Ann Thorac Surg 1975; 19: 426-35.

[5] Olinger GN, Bonchek L, Geiss D. Noncoronary collateral distribution in coronary artery disease. Ann Thorac Surg 1981; 32: 554-7.

[6] Hudson C, Moritz A. Wearn J. The extracardiac anastomosis of the coronary arteries. J Exp Med 1932; 56: 919-26.

[7] Picichè M, Kingma JG, Fadel E, et al. Enhancement of noncoronary collateral circulation: The hypothesis of an alternative treatment for ischemic heart disease. Med Hypotheses 2000; 74: 21-3.

[8] Picichè M. La circulation collatérale non coronarienne: Histoire, nature et rôle potentiel. Chirurgie Thoracique et Cardiovasculaire $2011 ; 15(3): 150-3$

[9] Loukas M, Hanna M, Chen J, Tubbs RS, Anderson RH. Extracardiac coronary arterial anastomoses. Clin Anat 2011; 24(2): $137-42$

[10] Moberg A. Anastomosis between extracardiac vessels and coronary arteries via internal mammary arteries. Acta Radiol Diagn 1967; 6: 263-72.

[11] Grant RT, Regnier M. The comparative anatomy of the cardiac coronary vessels. Heart 1926; 13: 285-317.

[12] Halpern MH, May MM. Phylogenetic study of the extracardiac arteries to the heart. Am J Anat 1958; 102(3): 469-80.

[13] Schaper W, Jageneau A, Xhonneux R. The development of collateral circulation in the pig and dog heart. Cardiologia 1967; 51: 321-35.

[14] Halpern MH. The dual blood supply of the rat heart. Am J Anatomy 1957; 101(1): 1-15.

[15] Von Haller A. First Lines of Physiology. $1^{\text {st }}$ American ed.: Troy O.Penniman 1803 . 
[16] Langer L. Die Foramina Thebesii in herzen des Menschen. SitzBericht. Wien, Math-Nat Akad. Wissensck, Wien 1880.

[17] Woodruff, C. E. Studies on the vasa vasorum. Am J Pathol 1926; 2(6): $567-70$.

[18] Wearn, JT. The extent of the capillary bed of the heart. J Exp Med 1928; 47: 273-90.

[19] Robertson TF. The vascularization of the epicardial and periaortic fat pads. Am J Pathol 1930; 6(2): 209-15.

[20] Gross L. The blood supply to the heart. New York: Hoeber 1921.

[21] Monckeberg J. Ifandbuch der speziellen pathologischen Anatomie und Histologie. Berlin: Julius Springer 1924.

[22] Spalteholz, W. Die Arterien der Herzwand. Leipsic: Hirzel 1924

[23] Warburg, EJ. Ueber den Coronarkreislauf und ueber die Thrombose einer Coronararterie. Acta $\sim$ ned. Scan 1930; 73: 425.

[24] Krarsner HT. Coronary arteries. In: Survey on atherosclerosis. Josiah Macy Jr Foundation, New York: Mac Millian 1933.

[25] Moberg A. Anastomosis between extracardiac vessels and coronary arteries. Acta Radiol 1967; 6:177-92.

[26] Moberg A. Anatomical and functional aspects of extracardial anastomoses to the coronary arteries. Path Microbiol 1967; 30: 689-94.

[27] Moberg A. Anastomoses between extra cardiac vessels and the coronary arteries. Acta Med Scand 1968; 485: 5-25.

[28] Bjork L. Angiographic demonstration of extracardiac anastomoses to the coronary arteries. Radiology $1966 ; 87: 274-7$.

[29] Sanerkin NG. Extracardiac anastomosis in coronary ostial occlusion. Br Heart J 1968; 30: 440-2.

[30] Kawasuji M, Murakami S, Watanabe Y, Iwa T. Coronary artery steal via a large anastomosis between the coronary and bronchial arteries successfully treated by surgical division. Thorac Cardiovasc Surg 1984; 32: 119-21.

[31] Goldstein SM, Nelson RL, McConnell DH, Buckberg GD. Cardiac arrest after aortic cross-clamping: effects of conventional vs pharmacologic arrest on myocardial supply/demand balance. Surg Forum 1975; 26: 271-3.

[32] Baile EM, Ling H, Heyworth JR, Hogg JC, Pare PD. Bronchopulmonary anastomotic and noncoronary collateral blood flow in humans during cardiopulmonary bypass. Chest 1985; 87(6): 749-54.

[33] Binak K, Harmanci N, Sirmaci N, Ataman N, Ogan H. Oxygen extraction rate of the myocardium at rest and on exercise in various conditions. Br Heart J 1967; 29(3): 422-7.

[34] Do Valle PV, Barcia A, Bargeuon LM Jr, Karp RB, Kirklin JW. Angiographic study of supravalvular aortic stenosis and associated lesions. Report of five cases and review of the literature. Ann Radiol (Paris) 1969; 12: 779-96.

[35] Jefferson K, Rees S, Somerville J. Systemic arterial supply to the lungs in pulmonary atresia and its relation to pulmonary artery development. Br Heart 1972; 34: 418-27.

[36] Nordenstram B. Selective catheterization and angiography of bronchial and mediastinal arteries in man. Acta Radiol Diagn (Stockh) 1974; 6: 13-25.

[37] Singh RN, Varat MA. Acquired internal mammary-to-coronary artery communication. Cathet Cardiovasc Diagn 1982; 8: 281-5.

[38] Kajinami K, Takekoshi N, Yoshio H. Internal mammary-tocoronary artery communication in a patient with occluded coronary artery. Am Heart J 1993; 125: 1428-30.

[39] Knight C, Webster G, Mulcahy D. Collateral growth between the left internal mammary and left anterior descending arteries following coronary artery bypass surgery. Int J Cardiol 1994; 43: 107-9.

[40] Salachas A, Antonellis I, Margaris N, et al. Communication between a nongrafted left internal mammary artery and left anterior descending coronary artery following saphenous vein bypass grafting. Cathet Cardiovasc Diagn 1997; 40: 170-2.

[41] Aras D, Topaloglu S, Cagli K, Ergun K, Ozeke O, Korkmaz S. A rare form of communication between the left internal thoracic artery and the left anterior descending artery. J Invasive Cardiol 2006; 18: E209-10.

[42] Chung DC, Choi J, Song Y, Lim A, Park K, Choi Y. Polyarteritis Nodosa Complicated by Chronic Total Occlusion Accompanying Aneurysms on All Coronary Arteries. Korean Circ J 2012; 42: 568570.
[43] Monopoli DE, Politi L, Sgura F, Rossi R, Modena MG, Sangiorgi GM. Acute myocardial infarction with occlusion of all three main epicardial coronary arteries: when Mother Nature takes care more than physicians. Heart Vessels 2011; 26(2): 222-5.

[44] Leary T, Wearn J. Two cases of complete occlusion of both coronary orifices. Am Heart J 1929; 5: 412-23.

[45] Thorel CH. Pathologie der Kreislauforgane. Ergebn Allg Pathol Path Anat 1903.

[46] Picichè M. The history of myocardial revascularization before the advent of cardiopulmonary bypass. In: Picichè M, Ed. Dawn and Evolution of Cardiac Procedures: Research Avenues in Cardiac Surgery and Interventional Cardiology. Springer-Verlag: Heidelberg 2012; pp. 65-77.

[47] Beck CS. Development of a new blood supply to the heart by operation. Ann Surg 1935; 102: 801-13.

[48] Beck CS, Leighninger DS. Operations for coronary artery disease, JAMA 1954; 156: 1226-33.

[49] Picichè M. Le défi de la revascularisation myocardique dans les années 1930 et 1940: Hommage à Claude Schaeffer Beck. Chirurgie Thoracique et Cardiovasculaire 2013; 17(4): 199-200.

[50] O'Shaughnessy L. The pathology and surgical treatment of cardiac ischemia. Bristol Med J 1937: 54: 109-26.

[51] Lezius A. Die kunstliche Blutversorgung des Herzmuskels. Arch Klin Chir 1937; 189: 342-6.

[52] Kline JL, Stern H, Bloomer WE, Liebow AA. The application of an induced bronchial collateral circulation to the coronary arteries by cardiopneumonopexy. Am J Pathol 1956; 4: 663-93.

[53] Baronofsky ID, Hannon DW. A comparison of cardiojejunopexy with other methods of revascularizing the heart. Surgery 1956 40(6): 1111-27.

[54] Dragstedt LR, Ragins H, Lyon ES, Dragstedt LR. Gastrocardiopexy; an experimental study. AMA Arch Surg 1956; 73(1): 1-5.

[55] Anyanwu E, Konermann C, Klinke F, Dittrich H. The influence of non-coronary collateral blood supply on the electively arrested heart during ischemia and reperfusion. Res Exp Med 1983; 182(2): 111-26.

[56] Sajja LR, Mannam G. Internal thoracic artery: Anatomical and biological characteristics revisited. Asian Cardiovasc Thorac Ann 2015; 23(1): 88-9.

[57] Murray AC, Rozen WM, Alonso-Burgos A, Ashton MW, GarciaTutor E, Whitaker IS. The anatomy and variations of the internal thoracic (internal mammary) artery and implications in autologous breast reconstruction: clinical anatomical study and literature review. Surg Radiol Anat 2012; 34(2): 159-65.

[58] Shalom F, Vunnamadala SP, Gibbs TS. An angiographic consideration prior to coronary bypass graft surgery: importance of routine selective angiography of the internal mammary artery prior to myocardial revascularization. J Invasive Cardiol 2012; 24(5): E87-9.

[59] Andreou AY, Iakovou I, Vasiliadis I, Psathas C, Prokovas E, Pavlides G. Aberrant left internal thoracic artery origin from the extrascalenic part of the subclavian artery. Exp Clin Cardiol 2011; 16(2): 62-4.

[60] Hayashida N, Kai E, Enomoto N, Aoyagi S. Internal thoracic artery as a collateral source to the ischemic lower extremity. Eur J Cardiothorac Surg 2000; 18(5): 613-6.

[61] Yourdakul M, Tola M, Ozdemir E, Bayazit M, Cumhur T. Internal thoracic artery-inferior epigastric artery as a collateral artery pathway in aortoiliac occlusive disease. J Vasc Surg 2006; 43(4): 707-13.

[62] Guglielmini C, Torbidone A, Mazzi A, Morandi F, Diana A. Internal thoracic artery-caudal epigastric artery as a collatera pathway in a dog with aortic occlusion: a case report. Vet J 2007: 10 .

[63] Korkut AK, Cetin G, Suzer K. Internal thoracic artery as main blood supply to the lower limbs. Case report. Acta Chir Belg 2006; 106: 243-5.

[64] Chaff A. The internal mammary artery: an overlooked collateral pathway to the leg. Radiology 1976; 121: 621-4.

[65] Shalom F, Vunnamadala SP, Gibbs TS. An angiographic consideration prior to coronary bypass graft surgery: importance of routine selective angiography of the internal mammary artery prior to myocardial revascularization. J Invasive Cardiol 2012; 24(5): E87-9. 
[66] Picquet J, Enon B. Thoraco-epigastric anastomosis in Leriche syndrome. Surgery 2007; 142(1): 121-2.

[67] Arnold JR, Greenberg J, Reddy K, Clements S. Internal mammary artery perfusing Leriche's syndrome in association with significant coronary arteriosclerosis: four case reports and review of literature. Catheter Cardiovasc Interv 2000; 49(4): 441-4.

[68] Hayashida N, Kai E, Enomoto N, Aoyagi S. Internal thoracic artery as a collateral source to the ischemic lower extremity. Eur $\mathbf{J}$ Cardiothorac Surg 2000; 18(5): 613-6.

[69] Picichè M, Fadel E, Kingma JG Jr, et al. Blood flow to the heart from noncoronary arteries: an intriguing but challenging research field. Cardiovasc Revasc Med 2012; 13(1): 25-9

[70] Vineberg A, Walker J. The surgical treatment of coronary artery heart disease by internal mammary artery implantation: report of 140 cases followed up to thirteen years. Dis Chest 1964; 45:190206.

[71] Picichè M. Histoire de la Chirurgie Cardiaque. Site de la Société Française de Chirurgie Thoracique et Cardiovasculaire. Dossier. http://www.sfctcv.net/pages/college.php.

[72] Marx R, Jax TW, Kelm M, Schoebel FC, Strauer BE. Vineberg graft: flow reserve of bilateral implantation after 27 years. Ann Thorac Surg 2001; 71(1): 341-3.

[73] Hughes MM. Bilateral functioning Vineberg grafts. A 25-years follow-up. Chest 1997; 111: 824-6.

[74] Unger EF, Sheffield CD, Epstein SE. Creation of anastomoses between an extracardiac artery and the coronary circulation. Proof that myocardial angiogenesis occurs and can provide nutritional blood flow to the myocardium. Circulation 1990; 82:1449-66.

[75] Sajja LR, Mannam G. Internal thoracic arter: anatomical and biological characteristics revisited. Asian Cardiovasc Thorac Ann 2015; 23 (1): 88-99.

[76] Unger EF, Shou M, Sheffield CD, Hodge E, Jaye M, Epstein SE. Extracardiac to coronary anastomoses support regional left ventricular function in dogs. Am J Physiol 1993; 264: 567-74.

[77] Picichè $M$, Kingma JG, Voisine $P$, Dagenais F, Fadel E. Angiogenesis and surgical or endovascular enhancement of noncoronary collateral circulation: A new research field. J Thorac Cardiovasc Surg 2010; 139 (6): 1675-6.

[78] Picichè M, Kingma JJ, Fadel E, et al. Enhancement of noncoronary collateral blood flow from the internal thoracic arteries: the theoretical and practical basis of an alternative method of myocardial blood supply. J Cardiovasc Surg 2011; 52(1):127-31

[79] Gibbon JH. Application of a mechanical heart and lung apparatus to cardiac surgery. Minn Med 1954; 37: 171-85.

[80] Caouette M. Research on cardiopulmonary bypass in North America. In: Picichè M, Ed. Dawn and evolution of cardiac procedures: Research avenues in cardiac surgery and interventional cardiology. Springer-Verlag, Heidelberg 2012; 115-25

[81] Picichè M. The history of surgical research. In: Picichè M, Ed. Dawn and evolution of cardiac procedures: Research avenues in cardiac surgery and interventional cardiology. Springer-Verlag, Heidelberg 2012; 11-17.

[82] Demaria RG, Al Yamani M. The history of surgery for ischemic heart disease and mechanical complications of myocardial infarction after the advent of cardiopulmonary bypass. In: Picichè M, Ed. Dawn and Evolution of Cardiac Procedures: Research Avenues in Cardiac Surgery and Interventional Cardiology. Springer-Verlag: Heidelberg 2012; pp. 265-71.

[83] Jonnesco T. Angine de poitrine guérie par la résection du sympathique cervicothoracique. Bull Acad Med Paris 1920; 84: 93102.

[84] O'Shaughnessy L. Experimental method of providing collateral circulation to the heart. Br J Surg 1936; 23: 665-70.

[85] Fauteux M, Palmer JH, Treatment of angina pectoris of atheromatous origin by ligation of great cardiac veins. Can Med Assoc J 1941; 45, 295-9.

[86] Beck CS. Principles underlying the operative approach to the treatment of myocardial ischemia. Ann Surg 1943;118(5): 788-806

[87] Schildt P, Stanton E, Beck CS. Communications between the coronary arteries produced by the application of inflammatory agents to the surface of the heart. Ann Surg 1943; 118(1): 34-45.

[88] Fieschi D. Criteri anatomo-fisiologici per intervento chirurgico lieve in malati di infarto and cuore e di angina. Arch Ital Chir 1942; 63: 305-10.
[89] Battezzati M, Tagliaferro A, De Marchi G. La legatura delle due arterie mammarie interne nei disturbi di vascolarizzazione del miocardio. Minerva Medica 1955; 46: 1178-88.

[90] Battezzati M, Tagliaferro A, Cattaneo AD. Clinical evaluation of bilateral internal mammary artery ligation as treatment coronary heart disease. Am J Cardiol 1959; 4(2): 180-3.

[91] Battezzati M, Tagliaferro A, Cattaneo AD, Donini I, Bachi V. On the anastomostic relations between the region of the internal mammary arteries and the coronary arterial circulation. Minerva Chir 1959; 14: 869-73.

[92] Battezzati M, Tagliaferro A, Cattaneo AD. Bilateral internal mammary arteries ligation in the coronary artery disease. Sci Med Ital 1959; 7(3): 463-85.

[93] Battezzati M, Tagliaferro A, Cattaneo AD. Bilateral ligation of the internal mammary artery in coronary insufficiency. J Int Coll Surg 1958; 30(4): 501-6.

[94] Battezzati M, Cattaneo AD, Tagliaferro A, Donini I, Bruno F. Changes in systemic arterial pressure, central venous pressure and cardiac pressures induced by acute occlusion of the descending branch of the left coronary artery and after bilateral ligation of the internal mammary arteries; experimental study in dogs. Minerva Chir 1958; 3(3): 157-63.

[95] Battezzati M, Tagliaferro A, Cattaneo AD. Clinical evaluation of bilateral internal mammary artery ligation as treatment coronary heart disease. Am J Cardiol 1959; 4(2): 180-3.

[96] Glover RP, Davila JC, Kyle RH, Beard JC, Trout RG, Kitchell JR. Ligation of the internal mammary arteries as a means of increasing blood supply to the myocardium. J Thorac Surg 1957; 34 (5): 66178.

[97] Glover RP, Kitchell JR, Kyle RH, Davila JC, Trout RG. Experiences with myocardial revascularization by division of the internal mammary arteries. Chest 1958; 33: 637-57.

[98] Glover RP. A new surgical approach to the problem of myocardial revascularization in coronary artery disease. J Arkansas Med Society 1957; 54 (6): 223-34.

[99] Taber RE, Marchioro T. Observation on the hemodynamic effects of experimental internal mammary artery ligation. Arch Surg 1958; 76: 781-5.

[100] Kitchell JR, Glover RP, Kyle RH. Bilateral internal mammary artery ligation for angina pectoris; preliminary clinical considerations. Am J Cardiol 1958; 1: 46-50.

[101] Botham RJ, Rowe GG, Gale JW. Experimental evaluation of systemic and coronary arterial pressure response associated with ligation of the internal mammary and subclavian arteries. Am Heart J 1959; 58: 719-25.

[102] Cobb LA, Thomas GI, Dillard DH, Merendino KA, Bruce RA. An evaluation of internal-mammary-artery ligation by a double-blind technic. N Engl J Med 1959; 260: 1115-8.

[103] Dimond EG, Kittle CF, Crockett JE. Comparison of internal mammary artery ligation and sham operation for angina pectoris. Am J Cardiol 1960; 5: 483-6.

[104] Picichè $M$. La circulation collatérale cardiaque d'origine non coronarienne. Histoire, nature et rôle potentielle dans la cardiopathie ischémique. Presses Académiques Francophones $2014 ; 1-84$.

[105] Stoller M, de Marchi SF, Seiler C. The Function of Natural Internal Mammary-to-Coronary Artery Bypasses and its Effect on Myocardial Ischemia. Circulation 2014; 129(25): 2645-52.

[106] Rosamond W, Flegal K, Furie K, et al. Heart disease and stroke statistics - 2007 update. A report from the American Heart association Statistics Committee and Stroke statistics Subcommittee. Circulation 2008; 117(4): e25-e146.

[107] Williams B, Menon M, Satran D et al. Patients with coronary artery disease not amenable to traditional revascularization: prevalence and 3-year mortality. Catheter Cardiovasc Interv 2010; 75(6): 88691.

[108] Burkhoff D, Jones JW, Becker LC. Variability of myocardial perfusion defects assessed by thallium-201 scintigraphy in patients with coronary artery disease not amenable to angioplasty or bypass surgery. J Am Coll Cardiol 2001; 38(4): 1033-9.

[109] Kim MC, Kini A, Sharma SK. Refractory angina pectoris: mechanism and therapeutic options. J Am Coll Cardiol 2002, 39(6): 923-34.

[110] Kiernan TJ, Boilson BA, Sandhu GS, et al. Nonrevascularizable coronary artery disease following coronary artery bypass graft 
surgery: a population-based study in Olmsted County, Minnesota. Coron Artery Dis 2009; 20(2): 106-11.

[111] Antzelevitch C. Ranolazine: a new antiarrhythmic agent for patients with non-ST-segment elevation acute coronary syndromes? Nat Clin Pract Cardiovasc Med 2008; 5(5): 248-9.

[112] 112. Borer JS, Tardif JC. Efficacy of Ivabradine, a Selective I Inhibitor, in patients with chronic stable angina pectoris and diabetes mellitus. Am J Cardiol 2010; 105 (1): 29-35.

[113] The IONA Study Group. Effect of nicorandil on coronary events in patients with stable angina: the Impact Of Nicorandil in Angina (IONA) randomised trial. Lancet 2002; 359 (9314): 1269-75.

[114] Börjesson M. Visceral chest pain in unstable angina pectoris and effects of transcutaneous electrical nerve stimulation (TENS). Herz 1999; 24(2): 114-25.

[115] Taylor RS, De Vries J, Buchser E, Mike JL DeJongste. Spinal cord stimulation in the treatment of refractory angina: systematic review and meta-analysis of randomised controlled trials. BMC Cardiovasc Disord 2009; 9: 13.

[116] Urano, H, Ikeda H, Ueno T, Matsumoto, T, Murohara T, Imaizumi, T. Enhanced external counterpulsation improves exercise tolerance, reduces exercise-induced myocardial ischemia and improves left ventricular diastolic filling in patients with coronary artery disease. J Am Coll Cardiol 2001; 37 (1): 93-9.

[117] Saririan M, Eisenberg MJ. Myocardial laser revascularization for the treatment of end-stage coronary artery disease. J Am Coll Cardiol 2003; 41(2): 173-83

[118] Hakim G, Naber CK, Erbel R. New treatment option for patients with end-stage coronary artery disease by extracorporeal shockwave myocardial revascularization therapy. Cardiovascular Revasc Med 2008; 9 (2): 112-3.

(C) Marco Picichè; Licensee Bentham Open.

This is an open access article licensed under the terms of the Creative Commons Attribution-Non-Commercial 4.0 International Public License (CC BY-NC 4.0) (https://creativecommons.org/licenses/by-nc/4.0/legalcode), which permits unrestricted, non-commercial use, distribution and reproduction in any medium, provided the work is properly cited. 